\title{
Experimental study of multi-functional artificial reef parameters
}

\author{
M. ten Voorde ${ }^{1,2}$, J. S. Antunes do Carmo ${ }^{1}$, M. G. Neves ${ }^{2}$ \\ \& A. Mendonça ${ }^{2}$ \\ ${ }^{I} I M A R$ - Institute of Marine Research; University of Coimbra, Portugal \\ ${ }^{2}$ LNEC - Laboratório Nacional de Engenharia Civil, Portugal
}

\begin{abstract}
Portugal is one of many countries in the world to suffer from coastal erosion. Conventional ways of protecting a coastline appear to entail some disadvantages. An innovative and interesting way of protecting a local coastal zone by means of multi-functional artificial reefs avoids some of them.

A multi-functional artificial reef (MFAR) is a submerged breakwater which protects the local coastline and may also enhance the surfing possibilities and the environmental value of the local area. The structure has several positive sideeffects: first, it provides an unimpaired visual amenity; second, it offers tourist and economic benefits by improving the surfing.

A 2D physical study is under way at LNEC to investigate the relations between the breaker type and the submergence and the length of a MFAR. Two different geometries were tested for different incident wave characteristics and different water depths.

This paper presents the main characteristics of the physical experiments in progress in a wave flume to analyze the influence of the submergence and the length of a MFAR on the wave breaking type. The main preliminary conclusions are that the length of the reef doesn't have much influence on the breaker type and that the shorter the slope of the reef the more the wave breaks towards the crest.
\end{abstract}

Keywords: coastal protection, multi-functional artificial reefs, physical experiments, breaker type. 


\section{Introduction}

The economic importance of coastal zones has been growing in the past few decades, for a variety of reasons which include an increase in the population and related economic activities established near the coastlines. All this development has led to growing numbers of visitors wanting to enjoy a sandy beach on their holidays and practise outdoor sports such as surfing, sailing, fishing, etc. Unfortunately, many coastal zones are now suffering from erosion, and the aspects and characteristics that make the coasts so attractive could be among the causes of their gradual destruction.

In Portugal there are several examples of coastline erosion and degradation. One of these places is the Leirosa agglomeration, located to the south of Figueira da Foz, midway along the Portuguese West Atlantic coast (Antunes do Carmo et al. [1]; Schreck Reis et al. [2]). Heavy protection structures are neither allowed nor planned in the POOC (legal development plan for the coast), and so a multifunctional artificial reef (MFAR) is under study as an alternative measure to protect this very sensitive coastal dune system.

A MFAR (Figure 1, in which $\mathrm{S}$ is the submergence of the reef) is a relatively new approach to protecting a coast; it is a submerged breakwater that has several purposes. In addition to protecting the local coastline and improving the surfing possibilities, a MFAR can enhance the environmental value of the area where it is built. The advantages of a MFAR are that the visual impact is low and that with a proper design the down drift erosion can be minimal.

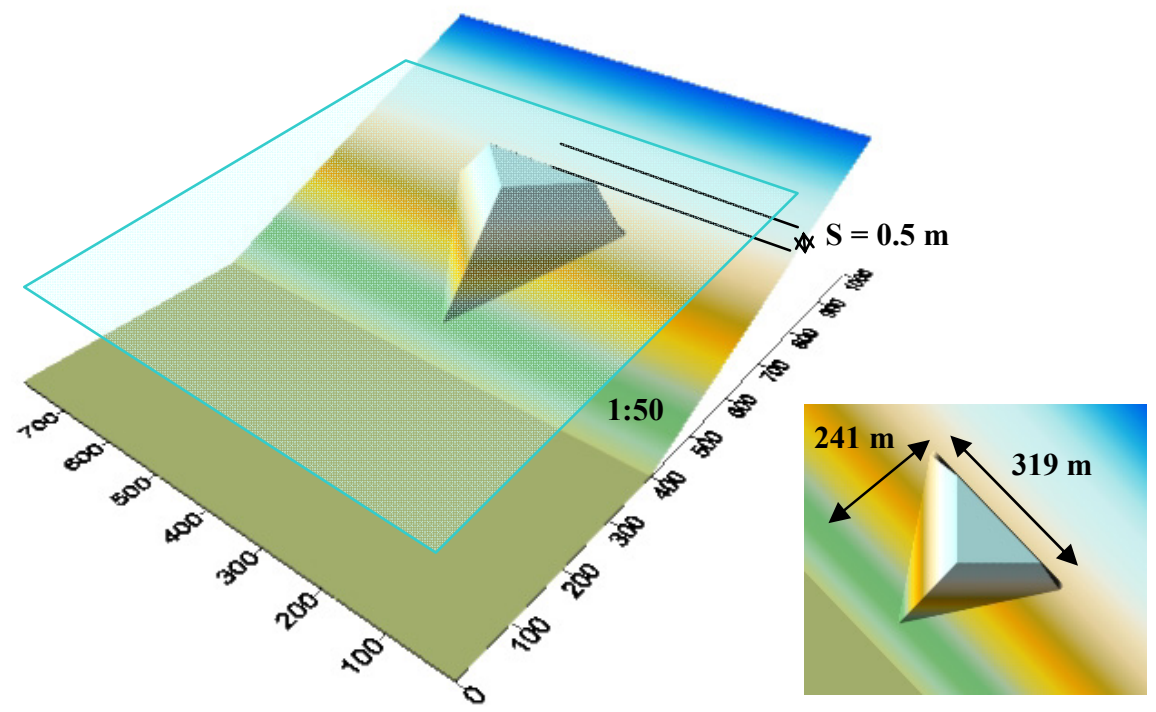

Figure 1: $\quad$ Multi-Functional Artificial Reef (MFAR).

Regarding the functionality of a MFAR, much research has been carried out on surfability, i.e. the possibility to surf a wave (for example Mead and Black [3] 
and Henriquez [4]). However, no research has yet been done on the influence of the submergence and length of the reef slope on the breaker type, even though this is important for the design of the reef regarding the surfability aspect.

According to Battjes [5] different types of wave breaking are categorized according to the offshore or inshore Iribarren number. The value of the (offshore/inshore) Iribarren number is determined by the bottom slope, the wave height (offshore/inshore) and the offshore wave length. However, Henriquez [4] notes that the submergence of a submerged reef also has an influence on the breaker type.

The length of the slope of the reef could also have an influence on the breaker type. In fact, when the reef has a fixed height and if the same wave conditions are used, deeper submergence automatically means a breaking point nearer the crest of the reef, which means a greater length of the slope experienced by the wave. In order to fill this gap of information, physical experiments have been prepared to investigate the relations between the breaker type and the submergence and the length of one MFAR.

This paper presents the experimental study conducted in a wave flume, to analyse the influences of the submergence and the length of the reef. After this introduction, the theoretical framework is described in which the theory behind the experiments is elucidated. After that, the experimental set-up is described and the main preliminary results are presented and discussed.

\section{Theoretical framework}

The term 'breaker type' refers to the form of a depth-limited wave at breaking and influences other breaking wave properties. Although there are several classifications of breaker type, it is generally accepted that waves break by spilling, plunging, collapsing, and surging (Galvin $[6,7])$.

Battjes [5] used the surf-similarity parameter, $\xi_{0}$ (equation (1)), to describe the breaker type on plane slopes and converted transition values determined by Galvin $[6,7]$ to find:

- $\quad$ surging or collapsing if $\xi_{0}>3.3$;

- plunging if $0.5<\xi_{0}<3.3$;

- $\quad$ spilling if $\xi_{0}<0.5$.

$$
\xi_{0}=\frac{s}{\sqrt{\frac{H_{0}}{L_{0}}}}
$$

where $\xi_{0}$ is the offshore Iribarren number, $\mathrm{s}$ is the bottom slope, $\mathrm{H}_{0}$ the offshore wave height and $\mathrm{L}_{0}$ the deep water wave length.

Smith and Kraus [8] performed a laboratory study with waves breaking over bars and over artificial reefs. They constructed the bar of marine plywood and tested six different design seaward angles and four design shoreward angles. They tested several combinations of shoreward and seaward angles of the bar, 
five regular wave conditions and three random wave conditions. They found for barred profiles the following transition values:

- $\quad$ surging or collapsing if $\xi_{0}>1.2$;

- plunging if $0.4<\xi_{0}<1.2$;

- $\quad$ spilling if $\xi_{0}<0.4$.

However, their results are for narrow crested artificial reefs, and the influences of the structure submergence and of the length of the slope on the breaker type and on the Iribarren number were not studied. Regarding the breaking behavior on artificial reefs with a smooth slope, as far as the authors know just one study has been conducted in a wave flume by Corbett and Tomlinson [9]. They performed a physical study for Noosa Main Beach in Australia on a permeable reef built of geotextile sand containers to investigate the wave breaking behavior and associated safety issues for an artificial reef.

The analysis of the results of these tests was especially focused on the breaker type, on the breaker wave height and on the breaker location as an indication for the safety of the submerged reef. However, even though several submergences were tested, no analysis of the relation between the breaker type and the corresponding Iribarren number was made. Furthermore, the influences of the length of the slope on the breaker type and the corresponding values of the Iribarren number were not investigated.

A fraction of the local wave length is taken as the minimum length of the reef, namely $1 / 4$ times the local wave length (Ten Voorde et al. [10]).

\section{Experimental set-up}

In order to get an idea about the influences of the length and of the submergence of the reef on the breaker type and its position, physical model tests were made in one of the LNEC's flume with the following dimensions: $73.0 \mathrm{~m}$ long, $3.0 \mathrm{~m}$ wide and $2.0 \mathrm{~m}$ deep. The model was operating according to Froude's similarity law, with a geometric scale of 1:10.

Two geometries were tested with the structure built of concrete with two different values for the length of the slope of the structure. The seaward slope of the reef was constant and equal to 1:10, a regular value for the side slope of a multi-functional artificial reef. The shoreward slope was 1:3. The slope of the foreshore is $1: 50$ and its length is $241 \mathrm{~m}$ for the lower geometry, and $164 \mathrm{~m}$ for the higher geometry, all in prototype scale. These values are at least $1.5 \mathrm{~m}$ times the wave length at the wave maker, for each depth tested.

Based on this, on the reef heights and on the reef submergences, the water depth at the wave maker was defined and varied from $7.5 \mathrm{~m}$ and $9.1 \mathrm{~m}$, in prototype scale.

Based on the assumption that the minimum length of the reef is $1 / 4$ times the local wave length, in order to get a good surfable wave, the minimum length of the reef in the experiments would be $15 \mathrm{~m}$ in prototype or less for reefs starting at a depth of $4 \mathrm{~m}$, for a maximum tested period of $10 \mathrm{~s}$ in the experiments. However, as the slope was $1: 10$, a length of $15 \mathrm{~m}$ gives a height of $1.5 \mathrm{~m}$. This 
values $(1.5 \mathrm{~m})$ was assumed to be too low, as larger periods should also break on the reef. A height of $1.9 \mathrm{~m}$ was decided to be the minimum value to be tested.

For the higher geometry, the length of the reef was almost twice the value for the lower geometry: $36 \mathrm{~m}$ in prototype scale. The width of the reef is $75 \mathrm{~m}$, in prototype scale. This value is at least one time the wave length. This wave length was determined for all periods tested and for the water depth at the start of the highest reef (largest submergence tested). Figure 2 shows the geometry parameters of the reef, and Tables 1 and 2 show the values of these parameters in the model scale. The lower and higher geometry are shown in Figure 3.
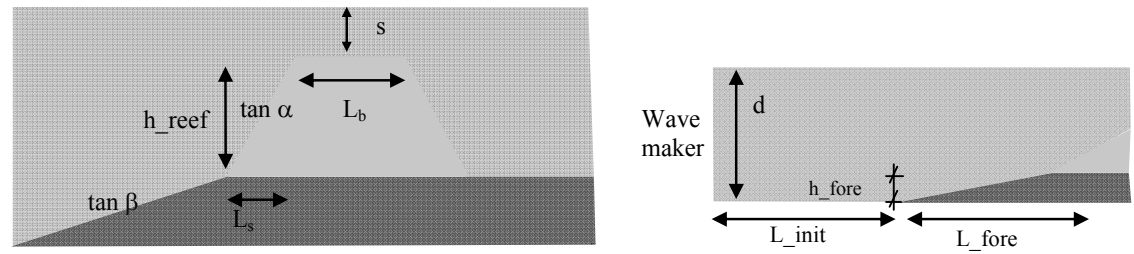

Figure 2: Definition of the geometric reef parameters tested.

Table 1: $\quad$ Values of some structure parameters in the model scale.

\begin{tabular}{|c|c|c|c|c|c|c|}
\hline Case & Material & $\mathrm{h} \_$reef $(\mathrm{m})$ & $\tan \alpha$ & $\tan \beta$ & $\mathrm{L}_{\mathrm{s}}(\mathrm{m})$ & $\mathrm{L}_{\mathrm{b}}(\mathrm{m})$ \\
\hline 1 & \multirow{2}{*}{ Concrete } & 0.19 & \multirow{2}{*}{$1: 10$} & $1: 50$ & 1.9 & \multirow{2}{*}{7.5} \\
\cline { 5 - 7 } & & 0.36 & & & 3.6 & \\
\hline 2 & &
\end{tabular}

Table 2: $\quad$ Values of more structure parameters in the model scale.

\begin{tabular}{|c|c|c|c|c|c|}
\hline Case & $\mathrm{h} \_$fore $(\mathrm{m})$ & $\mathrm{d}_{\min }(\mathrm{m})$ & $\mathrm{d}_{\max }(\mathrm{m})$ & $\mathrm{L}$ init $(\mathrm{m})$ & $\mathrm{L}$ _fore $(\mathrm{m})$ \\
\hline 1 & 0.48 & 0.75 & 0.91 & 18.2 & 24.2 \\
\hline 2 & 0.33 & 0.3 & & & 16.4 \\
\hline
\end{tabular}

For each reef geometry tested, 51 tests were executed, corresponding to 16 combinations of different values of wave height and submergence. Each wave height was tested for three different periods. Each test lasted 320 seconds, which corresponds to, at least, 100 waves.
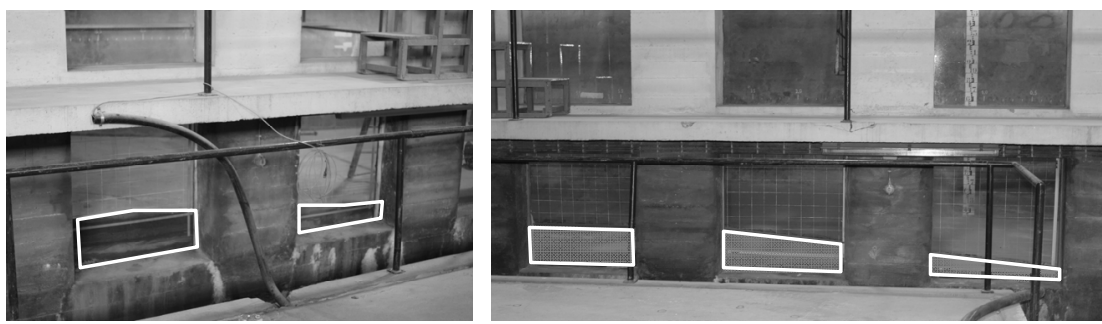

Figure 3: Lower geometry (left) and higher geometry (right). 
The choice of the submergence values was based on the following. In order to guarantee breaking conditions, a depth smaller than $0.8^{*} H_{b}$ was assumed to be necessary (Kaminsky and Kraus [11]), where the wave height at breaking, $H_{b}$, was chosen to be at minimum $1.0 * H_{0}$.

For all wave heights, a submergence of $0.8 * H_{b}$ or smaller was tested. However, in order to see if waves with larger submergences than that will also break, some wave heights have been tested with submergences of $\left(0.8^{*} H_{b}+\right.$ $0.04) \mathrm{m}$ or $\left(0.8 * H_{b}+2 * 0.04\right) \mathrm{m}$. Table 3 shows the test conditions.

Since it was the primary purpose of this experimental research to obtain accurate images of the breaker type, in each test a video camera recorded the breaker type of the breaking wave. A grid of 10 by $10 \mathrm{~cm}$ was made on the windows to help the measurements on the images taken from the videos.

Table 3: $\quad$ Test conditions (model scale).

\begin{tabular}{|c|c|c|c|}
\hline $\mathrm{H}_{\mathrm{s}}(\mathrm{m})$ & $\mathrm{S}(\mathrm{m})$ & $\mathrm{h}(\mathrm{m})$ & $\mathrm{T}_{\mathrm{p}}(\mathrm{s})$ \\
\hline \multirow{2}{*}{0.1} & 0.08 & 0.75 & \multirow{16}{*}{$\begin{array}{l}2.52 \\
2.84 \\
3.16\end{array}$} \\
\hline & 0.12 & 0.79 & \\
\hline \multirow{4}{*}{0.15} & 0.08 & 0.75 & \\
\hline & 0.12 & 0.79 & \\
\hline & 0.16 & 0.83 & \\
\hline & 0.2 & 0.87 & \\
\hline \multirow{4}{*}{0.2} & 0.12 & 0.79 & \\
\hline & 0.16 & 0.83 & \\
\hline & 0.2 & 0.87 & \\
\hline & 0.24 & 0.91 & \\
\hline \multirow{3}{*}{0.25} & 0.16 & 0.83 & \\
\hline & 0.2 & 0.87 & \\
\hline & 0.24 & 0.91 & \\
\hline \multirow{2}{*}{0.3} & 0.2 & 0.87 & \\
\hline & 0.24 & 0.91 & \\
\hline 0.35 & 0.24 & 0.91 & \\
\hline
\end{tabular}

Also 8 wave height gauges (WHG) were mounted in order to measure surface elevation at several positions along the wave flume, mostly positioned in the breaker zone.

The data collected would provide mainly wave height records, but it can also be used to obtain mean surface displacement (setup/setdown). Two sensors, gauge 1 and gauge 2, remained throughout the experiment at a seaward location close to the wave paddle, for control and repeatability tests.

Another gauge was located in the beginning of the foreshore slope and another at the beginning of the reef. The remained 4 gauges were mounted in the breaking zone. All tests were repeated with these 4 gauges $0.5 \mathrm{~m}$ moved in the direction of the end of the channel. In that way, at eight positions, $0.25 \mathrm{~m}$ from each other, in the breaking zone, the time series of the surface elevation were recorded. 


\section{Preliminary results}

From the tests made, some preliminary results have been achieved. In order to analyze the breaking type in a more convenient way, the results were divided into 5 categories, according to the Iribarren number:

- smaller than 0.6,

- from 0.6 to 0.8 ,

- from 0.8 to 1.0 ,

- from 1.0 to 1.2 and

- larger than 1.2.

The conclusions are here presented for each category and are illustrated by comparing pictures for two different geometries of the reef with the same submergences that illustrate the results. In these pictures, $\mathrm{Hm}$ is the mean wave height, $\mathrm{Tm}$ is the mean wave period in the wave gauge at a length of $5.1 \mathrm{~m}$ from the wave maker (gauge 1), $\mathrm{S}$ is the submergence and Ir is the Iribarren number. For Iribarren values larger than 1.2, no comparison can be made because there is just one result of a breaking wave for the lower geometry. It should be pointed out that the wave heights are not always the same for the lower and higher geometries.

The main conclusion is that, for all different categories, there is almost no difference in the breaker type for the different heights of the geometry. For $0.6<$ $\operatorname{Ir}<0.8$, the higher the submergence and the wave height, the better the tube is for surfing. Figure 4 illustrates the results and shows the breaker type for the lower and higher geometries, for a submergence of $0.16 \mathrm{~m}$.

Based on these results, a first preliminary conclusion can be made, which is that the length of the reef does not have much influence on the breaker type. However, the submergence could have an influence, at least for some values of the Iribarren number.
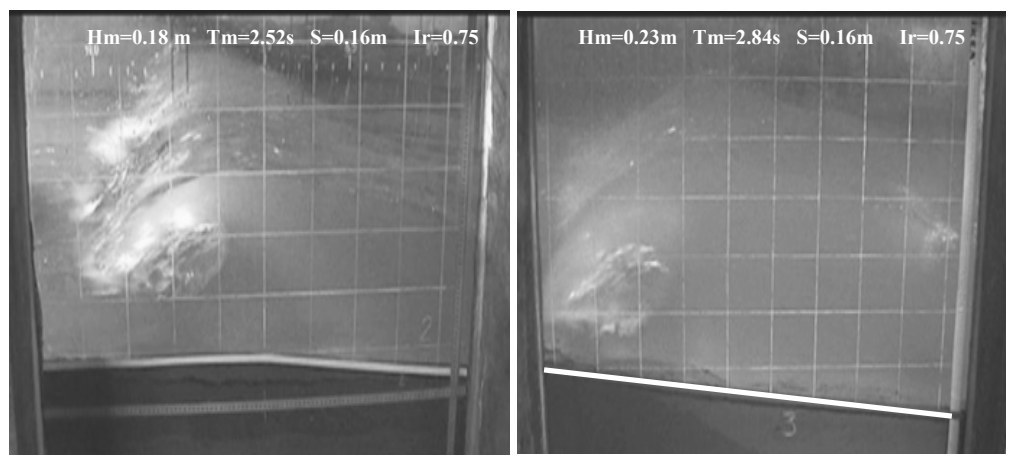

Figure 4: $\quad$ Breaker type for the lower (left) and higher (right) geometries, for $0.6<\operatorname{Ir}<0.8$.

However, on the other hand, with regards to the breaker position, there are differences in the results for different lengths or submergences of the reef. For Ir 
$<1.2$, the breaker position is more towards the seaward slope of the reef in the case of the higher geometry and for the same submergence. For $\operatorname{Ir}<0.8$ the difference is between $30 \mathrm{~cm}$ and $40 \mathrm{~cm}$ and reduces to between $10 \mathrm{~cm}$ and $20 \mathrm{~cm}$ for $0.8<\operatorname{Ir}<1.0$. This can be observed in Figure 5, for $\operatorname{Ir}<0.6$, which shows the breaker type for the lower and higher geometries, for a submergence of 0.24 $\mathrm{m}$. For the lower geometry and for the larger wave height tested with large submergences of 0.20 and $0.24 \mathrm{~m}$, most of the waves break before the reef starts. This is due to the fact that the breaker depth for these large wave heights was larger than the depth of the start of the reef. Based on these results, a second preliminary conclusion can be made, which is that the length has an influence on the breaker position and that the shorter the slope of the reef the more the wave breaks towards the crest.
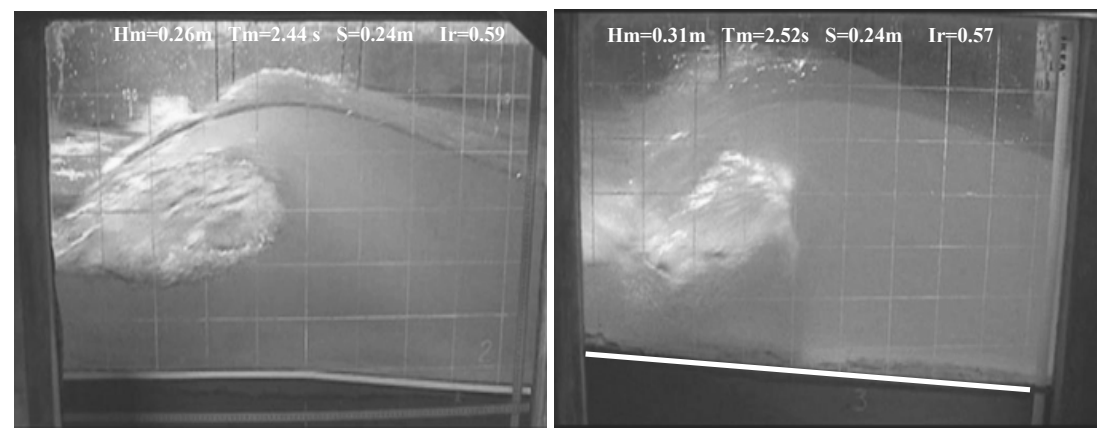

Figure 5: $\quad$ Breaker type for the lower (left) and higher (right) geometries, for Ir $<0.6$.

\section{Conclusions}

Multi-functional artificial reefs (MFARs) are submerged breakwaters that serve several purposes. As well as protecting the local coastline, they enhance surfing possibilities and/or increase the environmental value of the area where they are situated. MFARs have new promising aspects, too: first, they provide an unimpaired visual amenity, and second, they can offer tourist and economic benefits by improving the surfing conditions.

A physical study has been carried out to investigate the influence of the length and the submergence of the reef on the breaker type and on the breaker position. Preliminary conclusions are that: (1) the length of the reef doesn't have much influence on the breaker type, (2) the shorter the slope of the reef the more the wave breaks towards the crest.

More conclusions will be drawn when all results are achieved. As geotextile is an interesting material to construct multi-functional artificial reefs, tests with the same geometries of the reef, using the same wave characteristics, are under way and results will be compared. 


\section{Acknowledgements}

The authors gratefully acknowledge the Portuguese Foundation for Science and Technology under the project PTDC/ECM/66516/2006 and the financial sponsorship of Ten Voorde's $\mathrm{PhD}$ research by the Instituto de Investigação Interdisciplinar, Coimbra, Portugal.

\section{References}

[1] Antunes do Carmo, J.S., Schreck Reis, C. and Freitas, H., 2006. Successful rehabilitation of a sand dune system. In: Proc. of the Sixth International Conference on Environmental Problems in Coastal Regions Including Oil and Chemical Spill Studies (Rhodes, Greece), pp. 195-204.

[2] Schreck Reis, C., Antunes do Carmo, J.S. and Freitas, H., 2008. Learning with Nature: A Sand Dune System Case Study (Portugal). Journal of Coastal Research, 24(6): 1506-1515.

[3] Mead, S.T. and Black, K.P., 2001. Predicting the breaking intensity of surfing waves. Journal of Coastal Research, Special Issue No. 29, pp. 5165.

[4] Henriquez, M., 2004. Artificial Surf Reefs. Delft, The Netherlands: Delft University of Technology, Master's thesis, 53p. www.waterbouw.tudelft.nl (accessed August 18, 2006).

[5] Battjes, J.A., 1974. Surf similarity. Proc. 14th International Conference on Coastal Engineering, p. 466-479.

[6] Galvin, C.J., 1968. Breaker type classification on three laboratory beaches. Journal of geophysical research, 73(12), p. 3651-3659.

[7] Galvin, C.J., 1972. Wave breaking in shallow water. Waves on beaches and resultant sediment transport. Academic Press, New York, N:Y., 413-456.

[8] Smith, E,R. and Kraus, N.C., 1991. Laboratory study of wave breaking over bars and artificial reefs. Journal of Waterway, Port, and Coastal Engineering, 117(4): 307-325.

[9] Corbett, B., Tomlinson, R., 2002. Noosa Main Beach Physical Modelling, Research Report No. 17, Griffith Centre for Coastal Management.

[10] Ten Voorde, M., Antunes do Carmo, J.S. and Neves, M.G., 2009. Designing a Preliminary Multi-Functional Artificial Reef to Protect the Portuguese Coast, Journal of Coastal Research, 25(1), pp 69-79.

[11] Kaminski, G., and Kraus, N.C., 1993. Evaluation of depth-limited wave breaking criteria. Waves '93, Amer. Soc. Civil Engineers, pp. 180-193. 